\title{
The Judicial Accounting Appraisal and Revelation of Manager Corruption in State-Owned Joint-Stock Companies
}

\author{
Hao QIN \\ Hainan Vocational College of Political Science and Law, Haikou, China
}

\begin{abstract}
In order to verify the criminal facts of managers' alleged corruption in state-owned joint-stock companies, this article will give a technological check and demonstration for the accounting documents involved in this corruption, utilizing the method of judicial accounting appraisal technology. Research shows that appraisal personnel need to accumulate appraisal methods and update their appraisal techniques, so that they can be in effective response to new challenges posed by various crime commitments and its covert.
\end{abstract}

KEYWORD: Company manager; Corruption; Judicial accounting appraisal

\section{INTRODUCTION}

Corruption refers to the act of state personnel in China and those in state organs, state-owned companies, enterprises, public institutions, people's organizations who are entrusted to manage state property, taking advantage of their position to illegally possess public property by means of embezzlement, steal and fraud etc. The features of corruption determine the certain link between its illegal behavior and some business activities. The appraisal of financial information, therefore, will inevitably need to be involved through appraisal of corruption cases, to find out the facts.

\section{INTRODUCTION TO THE CASE}

A pharmaceutical Corporated Company (hereinafter referred to as A Pharmaceutical Corporation) is a state-owned joint-stock enterprise of state standardization, which wholly-owns the stock equity in B trust investment company (hereinafter referred to as B investment company) and has two subsidiaries - medicine sales company and Treasure Bao Rentang. According to the clues to report, the suspect Wang, along with the deputy general manager Liu taking charging of sales and some others, misappropriated a small fortune of company capital, when assuming the office of general manager in the pharmaceutical corporation in the period between April 1996 and May 2007. It is reported that Wang and Liu and other suspects purchased a large number of house property in
Beijing, Shanghai, and Haikou with their illegal income, despite the fact that their company has been suffering from chronic deficit. On July 2, 2008, this examination center was commissioned by a municipal people's procuratorate to conduct a judicial accounting appraisal related to the corruption facts and its illegal amount owned by suspect Wang and Liu when they were in their term of office. Identification materials range from 486 copies of accounting documents, 191 copies of accounting vouchers, accounting statements and other financial data, to company regulations, sales commission regulations, receipts and payments of company capital, bank transfer, and related agreement, etc, during his presence.

\section{INSPECTION PROBLEMS}

\subsection{Claiming reward commission of $R M B$ $615,606.29$ on the false pretense of making payments}

On February 1, 2000, no.1 receipt voucher of A Pharmaceutical Corporation bank journal showed the receipt of the Beijing office payment amounting to RMB715,606.29. Accounting reads, borrowing, bank deposit RMB715,606.29; Loaning: accounts receivables RMB 715,606.29. On February 1, 2000, no.1 payment evidence of A Pharmaceutical Corporation showed the proof of payment transfer to A pharmaceutical sales company loans, totaling RMB748,193.79, with a check stub, and accounting reads, borrowing, other receivables-A pharmaceutical sales company, RMB748,193.79; 
Loaning, bank deposit, RMB 748,193.79. On February 22, 2000, a transfer check stub in A Pharmaceutical Sales Corporation indicated the paying of RMB615,606.29 for Haikou Securities of B Investment Company in the name of "making payments". However, no accounting treatment was processed but a single original voucher kept and attached to a receipt, later signed by Liu on September 6,2001. The receipt said that, "This is to confirm that I have received 615,606.29 Yuan of reward commissions from A Pharmaceutical Corporation (transfer from B investment compa".

\subsection{Claiming reward commission of 324,043.85 Yuan in the name of cash refund.}

On March 14, 2001, no.3040 evidence of payment in A Pharmaceutical Corporate reflected that 80,000.00 Yuan had been remitted to Liu, with the accounting treatment showing borrowing, accounts receivablesLiu, 80,000.00 Yuan; Loaning, cash 80,000.00 Yuan. On March 15, 2001, no.3041 evidence of payment in A Pharmaceutical Corporation reflected that RMB 100,000.00 payment had been refunded to Liu, which would be paid by company deposit, with the purpose of "profit surrender". Accounting treatment was like borrowing, accounts receivablesLiu,100,000.00 Yuan; Loaning, cash 100,000.00 Yuan. On March 22, 2001, no.3060 payment evidence of A Pharmaceutical Corporation revealed that 144,043.85 Yuan had been refunded to Liu, with the accounting treatment representing-borrowing, accounts receivables-Liu, 144,043.85 Yuan; Loaning, cash 144,043.85 Yuan. However, none of these three sums of money with the receipt later signed by Liu on April 13, 2001, saying that, "This is to confirm that I have received commission 80,000 Yuan, 100,000 Yuan, and 144,043.85 Yuan respectively for Liu from A Pharmaceutical Corporation" have attached to the specific payback rewards and benefit commission forms in the wake of careful professional examining.

\subsection{Claim for sales payment collection rewards of $R M B$ 20,265,552.19}

According to the information presented by Liu and summary sheets of sales, payment collection and benefit in Beijing and Zhejiang office in previous years, as well as from main business revenue, expense reimbursement and other accounts receivable subsidiary ledgers, there were a total of 20,788,489.69 Yuan during 1996 to 2005 in sales and 16,009,060.07 Yuan in actual payment collection, accounting for $77.01 \%$, and 20,265,552.19 Yuan in benefits, accounting for as high as $126.59 \%$ of payment collection. This severely went against the related regulations about benefits and commissions.

\section{ARGUMENTS AND CONCLUSION}

\subsection{Analytical Demonstration}

\subsubsection{The identification of Liu's total claim for $R M B$ 1,100,829.34 reward commission}

This is to identify that A Pharmaceutical Sales Company has transferred $615,606.29$ Yuan to Haikou Securities of B investment company.

This sum of money was paid by payments 748,193.79 Yuan transferred from A Pharmaceutical Corporation to A pharmaceutical marketing branch on February 22, 2000. And it was collected from ten clients of D pharmaceutical corporation in Beijing, adding up to RMB 100,000 Yuan surplus than $615,606.29$ payment. The transfer check serves a purpose of "payment", with the receipt saying "surplus sum remitted by general manager Liu" written by Wang, along with "Liu's savings in Hainan", according to Liu's written authorization. However, Wang's receipt said that "This sum of money belongs to Liu's personal income", and Liu's receipt on September 6, 2001 also declared "reward commission", which lacks in payment evidence. Doubtlessly, the suspects involved can hardly get self-justification. Thus, a conclusion is reached that Wang and Liu misappropriated 615,606.29 Yuan of company goods payment by means of paying debts and faking receipts.

This is to identify the return of Liu's goods payment RMB 324,043.85. A Pharmaceutical Corporation has received 166,685.40 Yuan from D Pharmaceutical Corporation in Beijing on April 23, 2001 and then remitted 161,179.20 Yuan to Liu's bank credit card. This can be identified that there exists a similarity in the approaches of company funds misappropriation, namely, through commission and benefit, totaling 1,100,829.34 Yuan.

\subsubsection{Identification of Liu's illegal claim for com- missions of 20,127,229.81 Yuan}

The related regulations of sales commission and benefit since 1996 in A Pharmaceutical Corporation mainly includes following items:

On September 8, 1996, the tenth article of additional advice on" 96 " marketing policy stipulated that, " payment collection should be due within 90 days, and one day in advance is eligible for $1 \%$ reward commission, and one day delay for $1 \%$ penalty". According to article 11, "people whose task fall short of $60 \%$ by the end of the year will not be eligible for benefit; for those above $60 \%$ will be eligible for the benefit in proportion to their tasks, and as for those who overfill the quota, not only can they enjoy the benefit but also $1 \%$ rating as a reward. " On July 21, 1999, the company issued a notice, saying" annual award in 1998 will be withdrawn based on the payment collection 
percentage, $1 \%$ above 5 million Yuan, and 2\% below 5 million Yuan."

Upon examining the summary sheets of sales, payment collection and benefit from Liu as well as Beijing Office and other relevant data, sales business in the charge of Liu was under performed as less than $60 \%$ during 1996 to 1998 , which was arguably not entitled to the reward commission; and though some sales digits were almost up to payment collection ratio, which allows reward commission RMB 138,322.38 according to the regulation, amounted to RMB 20,127,229.81 more of the violation.

\subsubsection{Identification of A Pharmaceutical Corpora- tion's repeated written-off accounts receivable}

According to the financial data provided by A Pharmaceutical Corporation, we found in the examination process that financial management was left in a total chaos for short of effective financial supervision in Wang's office terms. A Pharmaceutical Corporation has transferred a large sum of capital into its two subsidiaries-A Medicine Sales Company and Treasure Ren Tang, thus enabling the outside circulation of sales capital. But neither of these two subsidiaries has ever set up a general ledger and a detailed subsidiary ledger nor did they get an accountant voucher, except for a single original receipt. General Manager Wang, together with Deputy Manager Liu and other related personnel, taking advantage of corporate financial chaos, embezzled company capital in the name of benefit and reward commission.

By examining the no.47 transfer voucher on 31 December, 2000 and the one of no.36 on 30 May, 2001, accounting treatment in A Pharmaceutical Corporation showed that $1,019,436.69$ Yuan of accounts receivable were repeatedly written off. Therefore, there's a dire need to trace related units for further identification of washed capital whereabouts.

\subsection{Findings Identification}

This arrival of conclusion is on the grounds of exhaustive examination, analysis and demonstration of financial data during Wang and Liu's terms of office.

By taking advantage of their positions, suspects Wang and Liu obtained their ill-gotten public property, adding up to $1,100,829.34$ Yuan in collaboration, in the name of refund, benefit and reward commission during the period of 22 February 2000, 14 March 2001, and 24 April 2001.

Suspects Wang and Liu obtained more illicit commission of 20,127,229.81 Yuan in the course of their presence from April 1996 to May 2007. This severely damaged the interests of company.
Accounting treatment in A Pharmaceutical Corporation is not formal and rigorous at all. The unlawful sum of written-off came to $1,019,436.69$ Yuan in the period of 31 December, 2000 and 30 May, 2001.

\section{IDENTIFICATION OF INSPIRATION}

\subsection{Existing Flaws}

Though comparatively reasonable appraisal suggestions have been put forward on a fair and impersonal basis in the process of several months' elaborate investigation, examination, analysis as well as demonstration, devoted by experts and staff, since the day of task undertaking, there still remains three slight faults in this appraisal conduction after some hindsight.

\subsubsection{Existing Examining Materials are Not Fully- prepared}

Although the clients have collected most of the criminal information about suspects, a few of financial data are not yet available and missed due to deliberate damage and disordered accountant archives management. This may, to some extent, has a negative influence over the cognition of judicial accounting identification.

\subsubsection{Evidence of Chains of Illicit Commission in Extra Cash are Not Closely Interwoven}

It is mentioned in identification suggestions that illicit commission in extra cash is 20,127,229.81 Yuan, yet inadequate financial information about examination process has been well dug, which directly leads to less cogent arguments and loose proof chains, which contributes to somewhat questionable conclusions.

\subsubsection{Repeated Written-off Accounts Receivable Need To Be Further Identified}

A total amount of 1,019,436.69 Yuan of accounts receivable has been checked out in the case. Further convincing materials and investigations should be gathered and launched to solve problems like, who took charge of this sum of money, was it manipulated by anyone and where did it flow to. Even though there are some flaws in this identification activity, bulk of financial evidence examined is powerful and will not pose, if any, threats, as a whole, towards evidence potency of identification findings.

\subsection{Experience Drawn from Identification}

Through this case, we have mainly gained following experience of judicial accounting identification. 


\subsubsection{The Habitual Criminal Approaches Adopted by Corruption Suspects}

Normally, there covers three criminal approaches employed by suspects, such as embezzlement, robbery and fraud. However, with the improvement of offenders' professional quality, crime methods become increasingly covet, intricate and specialized. Thus, it is essential to get familiar with criminals' consistent crime-committing means, for ease of efficient identification of job occupation cases. Three means of crime are included in this case. To start with, illegal embezzlement of public funds using refund, benefit and reward commission as excuses; Secondly, unlawful possessions of company goods payment by means of returning debts and supplementing receipts; Thirdly, public funds misappropriation by repeated written-off accounts receivable; Fourthly, concealed accounts setting-up, in which massive funds can be injected and circulated. Besides, in recent years, common ways of crime-committing adopted by suspects are as follows:

Revenue tend not to be entered the account and funds transfer; Illegal distribution and public funds detention; Faking property, debt, cost and expense for extortions; Pretending purchase and counterfeiting payrolls for cash fraud; Submitting personal expenses in public, making a fraudulent application and claim of repeated reimbursement.

\subsubsection{Work Techniques for Judicial Accounting Ex- amination}

To cover up the extent of their corruption suspects tend to play tricks on financial data. We have summarized some checking skills as follows. Firstly, we need to confirm related financial data. This will be achieved by initial analysis and basic confirmed data, then applying accounting data as an outlet so as to purposefully examine the original voucher, tally book as well as accounting ledger and statement. The truth and legitimacy of them can be checked out by related business data, for the convenience of clues detecting. Then, we need to trace funds flow. That is to say, by examining each stage of funds circulation, all of them can be put into manageable level in judicial accounting, by supervising "leakage" and "evaporation" phenomenon. Thirdly, we need to examine goods payment accounts. Normally, this includes bank deposit, cash, payment, etc. By examining goods payment accounts, doubts and problems can be cleared, and evidence of financial data can be withdrawn. Fourthly, we need to examine account cussent. Account cussent refers to the payment in advance, overpayment, unpayment, underpayment in business trade, and mainly reflects in "trade accounts payable", "other accounts payable", "accounts receivable", "other accounts receivable", and "payment in advance" in financial accounting. This is the right point where criminals could cheat.

\subsubsection{Techniques to Identify Judicial Accounting}

On committing a crime, offenders tend to take chances with examination workers, and given that, identification personnel ought to master professional techniques in order to subdue criminals. We have accumulated the following ways to identify. The first one is comparison. It means by using correct accounting approaches and outcomes as a model to compare with financial results recorder in the case, we are able to check whether or not recorder information is reliable. The second one is, balance analysis, which refers to the way of reasoning and identifying whether a sum of money is realistic by checking balanced relationship between funds and data involved in the case. The third one is narrowing down the examining material into a smaller scope. This means we do not have to examine enormous material any longer but only do it on a manageable size. The fourth one is factors prioritizing, which intends to rank the factors recorded in cases based on their difficulty levels and then embrace each factor into the analysis range according to the levels from simple to hard. The fifth one is analytical review method, namely by using expertise and professional experience, arrive at a convincing conclusion on the basis of related financial information, and reasonable inference, validation, calculation, as well as verification of financial records of the appraisal for examination.

\section{REFERENCES}

[1] Wang Bei, Distinguish from Corruption and bribery in the Judicial Practice, vol. 24, People's Justice, 2010, pp. 53.

[2] Yuanying Meng, practical Litigation judicial accounting and case, Macao: the Chinese publishing house, 2002, pp. 39.

[3] Jingfang Dong, Method Discussion on Judicial Accounting Check Technology, vol. 4, Journal of shanxi Advanced Police College, 2009, pp. 69-70.

[4] Yu Chao, Judicial Accounting, Beijing: China procuratorial press, 2008, pp. 440.

[5] Huajie Zhao, A Study on Judicial Accounting Appraisal Technique, vol. 9, Journal of Law and Society, 2009, pp. 174. 